Research Paper

\title{
Carcinoma of the lower female genital tract in patients with genitourinary malformations: a clinicopathologic analysis of 36 cases
}

\author{
Liju Zong1', Wenze Wang'2, Yonglan $\mathrm{He}^{3}$, Ninghai Cheng1, and Yang Xiang ${ }^{1}$ \\ 1. Department of Obstetrics and Gynecology, Peking Union Medical College Hospital, Chinese Academy of Medical Sciences and Peking Union Medical \\ College, 100730, Beijing, China \\ 2. Department of Pathology, Peking Union Medical College Hospital, Chinese Academy of Medical Sciences and Peking Union Medical College, 100730, \\ Beijing, China \\ 3. Department of Radiology, Peking Union Medical College Hospital, Chinese Academy of Medical Sciences and Peking Union Medical College, 100730, \\ Beijing, China
}

$\triangle$ Corresponding author: Yang Xiang, Department of Obstetrics and Gynecology, Peking Union Medical College Hospital, Chinese Academy of Medical Sciences and Peking Union Medical College, No.1 Shuaifuyuan, Wangfujing Dongcheng District, 100730, Beijing, China. Tel.: +86 106529 6068; E-mail: xiangy@pumch.cn.

(c) Ivyspring International Publisher. This is an open access article distributed under the terms of the Creative Commons Attribution (CC BY-NC) license (https://creativecommons.org/licenses/by-nc/4.0/). See http://ivyspring.com/terms for full terms and conditions.

Received: 2018.10.08; Accepted: 2019.04.13; Published: 2019.06.02

\begin{abstract}
Background: Lower genital tract carcinomas that coexist with genitourinary malformations are rare. The aim of this study was to investigate the clinicopathologic characteristics and outcomes of patients with this rare joint condition. The aim of this study was to investigate the clinicopathologic characteristics and outcomes of these patients to analyze the associations among clinicopathologic features in this rare entity.

Methods: The medical records of patients with carcinoma of lower genital tract combined with genital tract malformations who were treated at Peking Union Medical College Hospital (Beijing, China) between January 1995 and December 2017 were retrospectively reviewed and a comprehensive literature review was performed. The correlations between variables were determined using Fisher's exact test.

Results: Thirty-six patients were identified, among whom 22 had cervical carcinoma, 10 had vaginal carcinoma, and two had carcinomas of both the cervix and vagina. The most common genital tract anomaly was uterus didelphys $(n=17)$, and $63.9 \%$ of patients had with urinary tract malformations. Twenty-five $(69.4 \%)$ had pathologically confirmed adenocarcinoma, 10 (27.8\%) had squamous cell carcinoma (SCC), and 1 had adenosquamous carcinoma. Patients with urinary tract malformations developed adenocarcinoma more frequently than those without malformations $(95.7 \%$ vs. $30.8 \% P<0.001)$. Compared with patients with $S C C$, patients with adenocarcinoma presented at a younger age ( 36.1 vs. 47.0 years, $P=0.011$ ), had more advanced stages disease $(57.7 \%$ vs. $10.0 \%$ were in stage II-IV, $P=0.022)$, and tended to have poorer five-year overall survival rates $(75.6 \%$ vs. $100.0 \%, P=0.279)$.

Conclusions: Patients with simultaneous malformations of the genital and urinary tracts had a high probability of developing adenocarcinoma. It is recommended that rigorous gynecologic exams with Pap smears and imaging analyses be performed periodically in women with genital malformations, as they may be at a risk of genital malignancies.
\end{abstract}

Key words: cervical carcinoma; vaginal carcinoma; unilateral renal agenesis; Müllerian duct anomalies

\section{Introduction}

Cervical carcinoma is the second most commonly diagnosed cancer and the third leading cause of cancer-related deaths among women in less developed countries [1]. Primary vaginal carcinoma is considered one of the rarest of malignant lesions, accounting for approximately $2 \%$ of all gynecologic malignancies.

Female genital tract congenital malformations are defined as congenital variations of the normal female anatomy resulting from aberrant embryonic development. They represent a common benign condition with a prevalence of $4-7 \%$ and an incidence 
of $0.2-0.4 \%$ in the general population [2]. Genital and urinary tract developmental anomalies often occur simultaneously owing to the common embryologic origin of these two organ systems. Approximately $20 \%$ of women with genital tract malformations have urinary tract developmental anomalies [3, 4]. While carcinomas of the lower genital tract and genitourinary malformations are relatively common, their coexistence is rarely reported.

Considering the high incidence of cervical carcinoma worldwide, the absolute number of cervical carcinomas in patients with genitourinary malformation might be expected to be very high, especially in less developed regions. However, the opposite is true, as the number of reported cases is low [5]. This may be because the incidence of cervical carcinoma in developed countries is very low; moreover, many less developed regions are less likely to be able to afford imaging prior to surgery or radiotherapy, resulting in a missed diagnose of genitourinary malformations. The majority of patients with malformations from the developing world may also go unreported even if they are detected. Most cases that have been reported were described in case reports. Therefore, the general clinical presentations, pathologic features, and outcomes of lower genital tract carcinoma in patients with genitourinary malformation remain unknown.

We performed a retrospective review of all patients with carcinoma of the lower genital tract and genitourinary malformation who were treated at a single tertiary hospital, and performed a comprehensive literature review. Our goal was to identify the clinicopathologic characteristics and outcomes of these patients, and to analyze the associations among clinicopathologic features in this rare entity.

\section{Methods}

\section{Patients}

The medical records of patients with carcinoma of the lower genital tract (i.e., the cervix, vagina, and vulva) and genital tract malformations (with or without congenital malformations of the urinary tract) who were treated at Peking Union Medical College Hospital (Beijing, China) between January 1995 and December 2017 were retrieved from the institutional database. All patients were required to have pathologically confirmed cervical and/or vaginal carcinoma on a central review by a gynecologic pathologist at our hospital. The diagnoses of genitourinary malformations were based on physical examination, surgical findings, intravenous urography, ultrasonography, computed tomography, and magnetic resonance imaging (MRI). Medical records were reviewed, and demographic, pathological, and treatment data, and vital statistics were extracted.

\section{Literature review}

We performed a diligent and comprehensive PubMed search for all studies published between January 1965 and December 2017 using the search terms "genitourinary malformations", "female genital tract anomalies", "renal agenesis", "Müllerian duct anomalies", "uterus didelphys" in combination with either "carcinoma of the cervix", "carcinoma of the vagina" or "carcinoma of the vulva". Additional articles were identified by cross-referencing.

\section{Statistics}

The presentations, treatments, and outcomes were summarized using descriptive statistics. The correlations between two variables were explored using Fisher's exact test. Quantitative variables were compared using Student's t-test. Survival curves were plotted using the Kaplan-Meier method and compared using the log-rank test. All statistical analyses were conducted using the SPSS software for Windows, version 20.0 (IBM Corporation, Armonk, NY, USA). A $P$-value $<0.05$ was considered statistically significant.

\section{Results}

Thirty-six female patients with carcinoma and congenital malformations of the genital tract were identified, including 12 from our institution and 24 from the literature [6-26]. Clinicopathologic features, treatments, and outcomes for patients treated at our institution are shown in Table 1, and those of patients previously from the literature are shown in Table 2.

\section{Clinicopathologic features}

The average patient age was 39.1 years (range, 20-69). None of the patients had a history of prenatal diethylstilbestrol (DES) exposure. The presenting symptoms for patients with available data are shown in Table 3; the intermenstrual vaginal bleeding durations experienced by 17 patients ranged from one week to five years. Of the 36 patients, 22 had cervical carcinoma, 10 presented with vaginal adenocarcinoma, two presented with carcinoma of both the cervix and vagina with the primary carcinoma site difficult to distinguish, and two had carcinoma of the cervix and vaginal septum. Human papillomavirus (HPV) testing results were available for eight patients; six were negative while two with SCC of the cervix were positive for HPV 16 (patients 11 and 12). 
Table 1. Clinical features in 12 patients with genital tract carcinomas and malformation treated at the PUMCH

\begin{tabular}{|c|c|c|c|c|c|c|c|c|}
\hline \multirow[t]{2}{*}{ No. } & \multirow[t]{2}{*}{ Age } & \multirow[t]{2}{*}{ Site \& Stage } & \multirow[t]{2}{*}{ Histology } & \multirow[t]{2}{*}{ Genitourinary malformation } & \multirow[t]{2}{*}{ Initial treatment } & \multirow[t]{2}{*}{ Course and further treatment } & \multicolumn{2}{|c|}{ Follow up } \\
\hline & & & & & & & Time & Outcome \\
\hline 1 & 36 & Cervix IIB & $\mathrm{AC}$ & URA, UD & $\begin{array}{l}\text { Radiotherapy, TAH+BSO, } \\
\text { chemotherapy }\left(\mathrm{TC}^{*} 6\right)\end{array}$ & $\begin{array}{l}\text { Local recurrence and distant metastases } \\
\text { at } 3 \mathrm{yr} . \text { chemotherapy }\left(\mathrm{TP}^{*} 6\right) \text {, } \\
\text { radiotherapy, distant metastases at } 5^{\text {th }} \mathrm{yr} \text {. }\end{array}$ & $7 \mathrm{yr}$. & DOD \\
\hline 2 & 53 & Vagina II & $\mathrm{AC}$ & URA, UD & CCRT ( no response), PE & Distant metastases at $1.5 \mathrm{yr}$. & $\begin{array}{l}2.5 \\
\text { yr. }\end{array}$ & $\begin{array}{l}\text { Alive with } \\
\text { cancer }\end{array}$ \\
\hline 3 & 20 & $\begin{array}{l}\text { Vagina, right } \\
\text { cervix I }\end{array}$ & $\mathrm{CCA}$ & HWWS (URA) & $\mathrm{LRH}+\mathrm{BSO}+\mathrm{PLA}+\mathrm{TV}$ & Uneventful & $3 \mathrm{yr}$ & NED \\
\hline 4 & 27 & $\begin{array}{l}\text { Vagina, right } \\
\text { cervix IIB }\end{array}$ & $\mathrm{AC}$ & HWWS (URA) & $\begin{array}{l}\text { CCRT, } \mathrm{LH}+\mathrm{BSO}+\mathrm{TV}, \\
\text { chemotherapy }\left(\mathrm{TC}^{*} 6\right)\end{array}$ & $\begin{array}{l}\text { Local recurrence and kidney failure after } \\
1 \text { yr. }\end{array}$ & $2 \mathrm{yr}$. & DOD \\
\hline 5 & 44 & Vagina II & $\mathrm{AC}$ & $\begin{array}{l}\text { URA, bicornuate uterus, vaginal } \\
\text { septum }\end{array}$ & $\begin{array}{l}\text { CCRT }\left(\mathrm{TC}^{*} 6\right) \text { and interstitial } \\
\text { brachytherapy }\end{array}$ & Uneventful & $1 \mathrm{yr}$. & NED \\
\hline 6 & 31 & $\begin{array}{l}\text { Double cervix, } \\
\text { vaginal } \\
\text { septum IIA }\end{array}$ & CCA & HWWS (URA) & $\begin{array}{l}\text { Chemotherapy }\left(\mathrm{TP}^{*} 3\right) \text {, } \\
\mathrm{LH}+\mathrm{BSO}+\mathrm{PPLA} \text {, chemotherapy } \\
\left(\mathrm{TP}{ }^{*}\right), \text { CCRT }\end{array}$ & $\begin{array}{l}\text { Local recurrence and distant metastases } \\
\text { after } 4 \text { months, chemotherapy }\left(\mathrm{TC}^{*} 3\right) \text { and } \\
\mathrm{PE}\end{array}$ & $\begin{array}{l}1.5 \\
\text { yr. }\end{array}$ & DOD \\
\hline 7 & 38 & Cervix IIA & $\mathrm{AC}$ & HWWS (URA) & $\mathrm{RH}+\mathrm{BSO}+\mathrm{PPLA}$, radiotherapy & Distant metastases after 1 year & $2 \mathrm{yr}$ & DOD \\
\hline 8 & 26 & $\begin{array}{l}\text { Double cervix } \\
\text { IVa }\end{array}$ & CCA & $\begin{array}{l}\text { UD, double cervix, double vagina, } \\
\text { vaginal atresia, vagino-vesical } \\
\text { fistula, imperforate anus }\end{array}$ & $\begin{array}{l}\mathrm{LSO} \text {, chemotherapy }\left(\mathrm{TP} * 3, \mathrm{PF}^{*} 2\right) \text {, } \\
\text { radiotherapy, } \mathrm{PE}\end{array}$ & Uneventful & $1 \mathrm{yr}$. & NED \\
\hline 9 & 26 & Vagina I & CCA & $\begin{array}{l}\text { microperforate hymen, multiple } \\
\text { renal cysts }\end{array}$ & chemotherapy (PF*5), PV, CCRT & Uneventful & 3 yr. & NED \\
\hline 10 & 52 & Cervix IIB & SCC & septate uterus & CCRT & $\begin{array}{l}\text { Distant metastases after } 14 \text { months, } \\
\text { chemotherapy }\left(\mathrm{TC}^{*} 5\right)\end{array}$ & $1 \mathrm{yr}$. & $\begin{array}{l}\text { Alive with } \\
\text { cancer }\end{array}$ \\
\hline 11 & 61 & Cervix IA1 & SCC & UD & $\mathrm{LH}+\mathrm{BSO}$ & Uneventful & 1.5 & NED \\
\hline 12 & 43 & Cervix IB1 & SCC & UD & $\mathrm{LH}+\mathrm{BSO}+\mathrm{PLN}, \mathrm{CCRT}$ & Uneventful & $\begin{array}{l}\text { yr. } \\
10 \\
\text { yr. }\end{array}$ & NED \\
\hline
\end{tabular}

Abbreviations: AC, adenocarcinoma; CCA, clear cell adenocarcinoma; CCRT, concomitant chemoradiotherapy; CIN, cervical intraepithelial neoplasia; DDP,

cis-Dichlorodiammine platinum; DOD, died of disease; HWWS, Herlyn-Werner-Wunderlich Syndrome; LSO, left salpingo-oophorectomy; NED, no evidence of disease; PE, pelvic exenteration; PF, platinum plus 5-fluorouracil; PV, partial vaginectomy; SCC, squamous-cell carcinoma; TC, paclitaxel plus carboplatin; TP, pacitaxel plus platinum;

$\mathrm{TV}$, total vaginectomy; UD, uterus didelphys; URA, unilateral renal agenesis.

Table 2. Clinical features in 24 patients with genital tract carcinomas and malformations identified from literature

\begin{tabular}{|c|c|c|c|c|c|c|c|}
\hline Authors & Age & Site \& Stage & Histology & genito-urinary malformation & Treatment & Follow up & outcome \\
\hline Plesinac-Karapandzic & 25 & Vagina II & $\mathrm{AC}$ & URA & Radiotherapy & $15 \mathrm{yr}$. & NED \\
\hline Plesinac-Karapandzic & 20 & Vagina III & MA & URA & Chemotherapy and radiotherapy & $11 \mathrm{yr}$. & NED \\
\hline Cordoba & 37 & Left cervix IIIA & $\mathrm{AC}$ & HWWS (URA) & aortic lymphadenectomy + CCRT & 30 Mos. & NED \\
\hline Platta & 34 & Cervix IIB & $\mathrm{AC}$ & Septate uterus & CCRT & 20 Mos. & NED \\
\hline Kawano & 33 & Right cervix IB1 & CCA & $\begin{array}{l}\text { Bicornuate uterus, double } \\
\text { cervix, URA }\end{array}$ & $\mathrm{MRH}+\mathrm{RSO}+\mathrm{PLA}$; radiation and chemotherapy & $10 \mathrm{yr}$. & NED \\
\hline Kaba & 49 & Right cervix IB1 & EAC & HWWS (URA) & $\begin{array}{l}\mathrm{RH}+\mathrm{BSO}+\mathrm{PPLA}+\text { omentectomy; radical } \\
\text { parametrectomy and proximal vaginectomy }\end{array}$ & 15 Mos. & NED \\
\hline Watanabe & 33 & $\begin{array}{l}\text { Right cervix, } \\
\text { vaginal septum } \\
\text { IVa }\end{array}$ & EAC & HWWS (URA) & $\begin{array}{l}\text { Chemotherapy }(\mathrm{TC})+\text { external radiation; anterior } \\
\text { pelvic exenteration }+\mathrm{TV}\end{array}$ & NA & NA \\
\hline Watanabe & 53 & Vagina I & CCA & HWWS (URA) & $\mathrm{RH}$ & NA & NA \\
\hline Talia & 41 & Vagina I & $\mathrm{AC}$ & $\begin{array}{l}\text { URA, double cervix and } \\
\text { bicornuate uterus }\end{array}$ & Hysterectomy, vaginal mass resection and right PLA & 2 Mos. & NED \\
\hline Uehara & 54 & Vagina I & CCA & $\begin{array}{l}\text { Bicornuate uterus, URA, vaginal } \\
\text { septum }\end{array}$ & anterior pelvic exenteration & 43 Mos. & NED \\
\hline Zeeshanuddin & 27 & Left vagina I & CCA & $\begin{array}{l}\text { UD, double cervix, double } \\
\text { vagina, URA, situs inversus }\end{array}$ & $\mathrm{RH}+\mathrm{PLA}+\mathrm{PV}, \mathrm{PE}$ after recurrence & NA & NA \\
\hline Tewari & 34 & Vagina I & EAC & MRKH syndrome & $\mathrm{BSO}+\mathrm{PLA}$, pelvic radiotherapy & 18 Mos. & NED \\
\hline Sporri & 49 & Left cervix IIA & CCA & $\begin{array}{l}\text { Bicornuate uterus, double cervix } \\
\text {, URA }\end{array}$ & $\begin{array}{l}\mathrm{RH}+\mathrm{BSO}+\mathrm{PLA} \text {, pelvic radiation and vaginal } \\
\text { irradiation }\end{array}$ & $4.5 \mathrm{yr}$. & NED \\
\hline GomezIrizarry & 44 & $\begin{array}{l}\text { Left cervix IB } \\
\text { Ovaries mets. }\end{array}$ & ASC & $\begin{array}{l}\text { UD, double cervix, double } \\
\text { vagina }\end{array}$ & $\mathrm{RH}+\mathrm{BSO}+\mathrm{PPLA}+$ omentectomy; CCRT & 26 Mos. & DOD \\
\hline Sugimori & 44 & Two cervices IIB & $\mathrm{AC}$ & $\begin{array}{l}\text { UD, vaginal septum, double } \\
\text { cervix }\end{array}$ & $\mathrm{RH}+\mathrm{PLA}+$ radiation & NA & NA \\
\hline Nordqvist & 34 & Cervix IIA & CCA & UD, double vagina, URA & $\mathrm{RH}+\mathrm{PV}+\mathrm{PLA}$ & $24 \mathrm{yr}$. & NED \\
\hline Nordqvist & 27 & Cervix IB & CCA & UD, double vagina, URA & $\mathrm{RH}$, Intracavitary + pelvic radiation. & $16 \mathrm{yr}$. & NED \\
\hline Loo & 45 & $\begin{array}{l}\text { Two cervices } \\
\text { IB1 }\end{array}$ & SCC & UD, double cervix & CCRT & $2 \mathrm{yr}$. & NED \\
\hline Lee & 45 & $\begin{array}{l}\text { Two cervices } \\
\text { IB1 }\end{array}$ & SCC & UD, double cervix & Radical radiotherapy & 3 yr. & NED \\
\hline Bakri & 29 & Two cervices & CIS & UD, double cervix & Cone & 2 yr. & NED \\
\hline Tam & 69 & $\begin{array}{l}\text { Two cervices } \\
\text { IB1 }\end{array}$ & SCC & $\begin{array}{l}\text { UD, double cervix, vaginal } \\
\text { septum }\end{array}$ & $\begin{array}{l}\mathrm{RH}+\text { partial resection of vaginal septum, } \\
\text { radiotherapy }\end{array}$ & NA & NA \\
\hline Fox & 30 & Two cervices IA & SCC & UD, double cervix & Hysterectomy & NA & NA \\
\hline Corbett & 56 & Right cervix IB1 & SCC & $\begin{array}{l}\text { UD, double cervix, vaginal } \\
\text { septum }\end{array}$ & Radiotherapy, extended hysterectomy+ PLA & $2 \mathrm{yr}$. & NED \\
\hline Gerbie & 40 & Cervix IB & SCC & URA, UD, rudimentary uterus & $\mathrm{RH}+\mathrm{PLA}$ & NA & NA \\
\hline
\end{tabular}


adenocarcinoma; MRKH syndrome, Mayer-Rokitansky-Kuster-Hauser syndrome; MRH, modified radical hysterectomy; NED, No evidence of disease; NA, not available; $\mathrm{PE}$, pelvic exenteration; PLA, Pelvic lymphadenectomy; PPLA, pelvic-paraaortic lymphadenectomy; PV, partial vaginectomy; RH, radical hysterectomy; RSO, right salpingo-oophorectomy; TC, paclitaxel and carboplatin; UD, uterus didelphys; URA, unilateral renal agenesis.
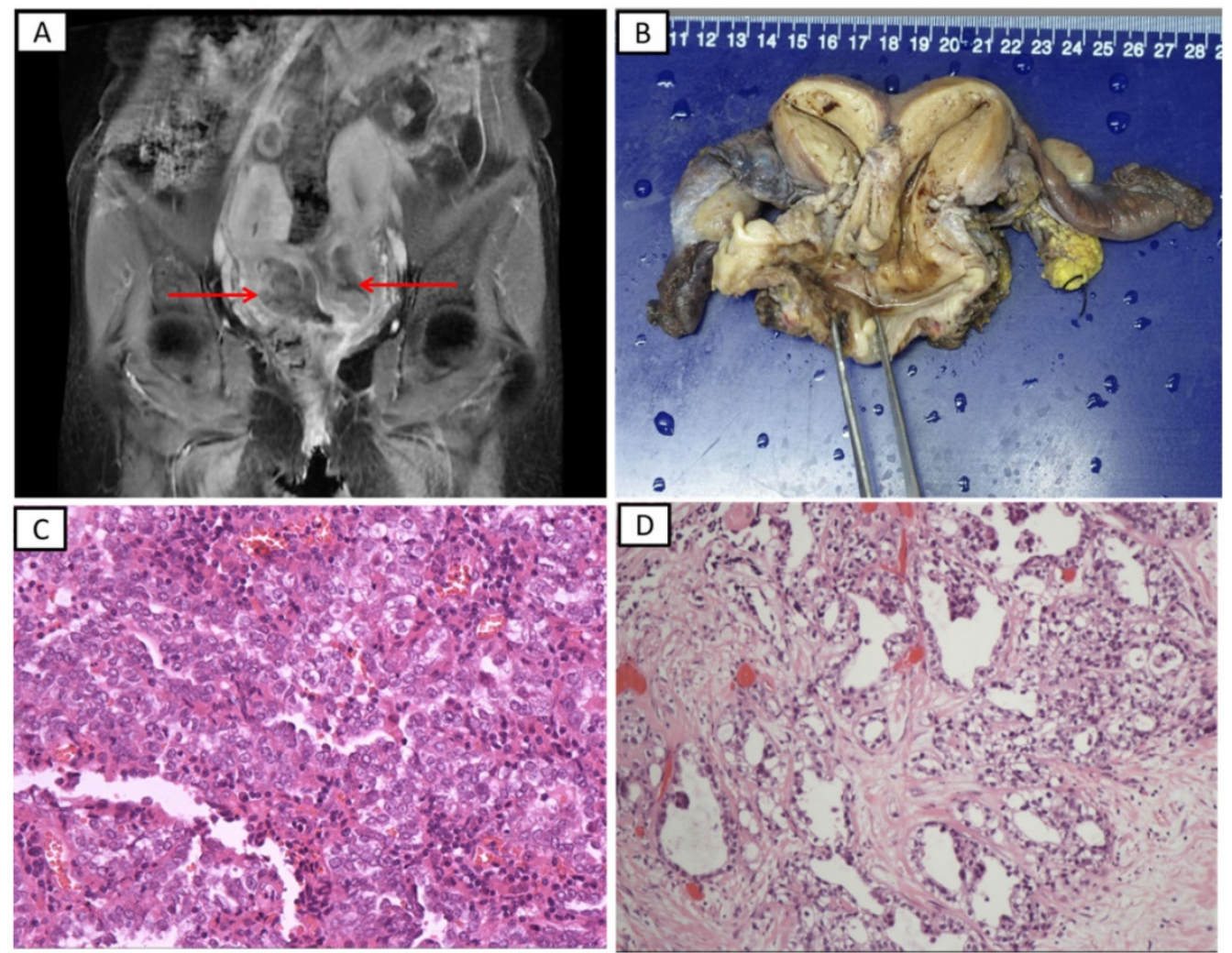

Figure 1. The representative radiological and pathological images in patients with lower genital tract carcinomas and genitourinary malformation treated at the Peking Union Medical College Hospital. A. T1-weighted magnetic resonance imaging (patient 8). A uterine cervical tumor was detected on both sides of the uterine cervix. B. Surgically resected tissues of a patient with Herlyn-Werner-Wunderlich syndrome (patient 6). C. Histopathological findings of a specimen showing clear cell adenocarcinoma of the vagina (hematoxylin-eosin staining, $\times 200$ ). D. Histopathological findings of a specimen showing clear cell adenocarcinoma of the cervix (hematoxylin-eosin staining, $\times 100)$

As most of the patients were documented before 2013, the European Society of Human Reproduction and Embryology/European Society for Gynecological Endoscopy classification [2] was not applied to female genital tract congenital anomalies. Therefore, we described the malformations as they appeared in the medical records and the literature. The most common genital tract anomalies were uterus didelphys $(n=17)$ and double cervix $(n=12)$. A representative MRI of a patient treated at our hospital is shown in Figure 1A (patient 8). This patient had complex female genitourinary anomalies which account for $<1 \%$ of all genital malformation in adults [27], including double cervix, double vagina, lower vagina atresia, congenital vagino-vesical fistula, and cloacal anomalies (imperforate anus). Uterine cervical tumors were detected on her two cervices; these also involved the mucosa of the bladder and rectum. Eight patients (22.2\%) had with Herlyn-Werner-Wunderlich syndrome (HWWS), which is also known as obstructed hemivagina and ipsilateral renal anomaly (OHVIRA), characterized by uterine didelphys, obstructed hemivagina, and ipsilateral renal agenesis. Gross specimens of the uterine and both adnexa from the patient with HWWS (patient 6) are shown in Figure 1B. Among the 20 patients with double cervices (including eight with HWWS), nine had carcinoma on one cervix, eight had carcinomas on two cervices, and three had no carcinoma of the cervix but had carcinoma of the vagina. Twenty-three patients $(63.9 \%)$ had with urinary tract malformation, including unilateral renal agenesis (URA) $(n=21)$, multiple renal cysts $(n=1)$ and vagino-vesical fistula $(n=1)$. It is notable that patient 2 , who was treated at our institution and had right renal agenesis and uterus didelphys, developed multiple primary malignant tumors. She was diagnosed with renal clear cell carcinoma and underwent left heminephrectomy in March 2010, and then, she was diagnosed with mucinous carcinoma of the breast in January 2015 and with vaginal adenocarcinoma in June 2015.

The International Federation of Gynecology and Obstetrics (FIGO) stages of 25 patients with cervical carcinomas are shown in Table 3; an additional patient was diagnosed with carcinoma in situ. Also shown are the FIGO stages of 10 patients with vaginal carcinoma. Of all 36 patients, $25(69.4 \%)$ had adenocarcinoma (including 10 adenocarcinoma, 11 
clear cell adenocarcinoma, three endometrioid adenocarcinoma, and one mesonephric adenocarcinoma), 10 (27.8\%) had SCC, and one (2.8\%) had adenosquamous carcinoma (ASC). All carcinomas of the vagina or vaginal septum were adenocarcinomas. Among the 26 patients with cervical carcinoma, $10(38.5 \%)$ had SCC, one $(3.8 \%)$ had ASC, and 15 (61.5\%) had adenocarcinoma. Among the 25 with cervical and/or vaginal adenocarcinoma, $10(40 \%)$ had clear cell adenocarcinoma and three $(12 \%)$ had endometrioid adenocarcinoma. The clinicopathologic features of the 36 patients are summarized in Table 3. The representative microscopic images of clear cell adenocarcinoma of the vagina (patient 2) and cervix (patient 8) are shown in Figure 1C and 1D, respectively.

Table 3. Clinicopathologic characteristics of 36 patients with genital malformations who developed carcinomas

\begin{tabular}{|c|c|c|c|}
\hline Variables & Category & $\mathrm{N}$ & $\%$ \\
\hline \multirow[t]{3}{*}{ Parity $(\mathrm{n}=30)$} & 0 & 10 & 33.3 \\
\hline & 1 & 8 & 26.7 \\
\hline & $\geq 2$ & 12 & 40.0 \\
\hline \multirow[t]{6}{*}{ Symptoms $(n=31)$} & Postcoital VB & 4 & 12.9 \\
\hline & Vaginal discharge & 3 & 9.7 \\
\hline & Intermenstrual VB & 17 & 54.8 \\
\hline & Periodic hematuria & 1 & 3.2 \\
\hline & Abnormal Pap smear & 3 & 9.7 \\
\hline & Postmenopausal VB & 3 & 9.7 \\
\hline \multirow[t]{3}{*}{ Sites of carcinoma } & Cervix & 22 & 61.1 \\
\hline & Vagina & 10 & 27.8 \\
\hline & Cervix and vagina & 4 & 11.1 \\
\hline \multirow[t]{4}{*}{ *FIGO stage of cervical carcinoma $(n=25)$} & I & 13 & 52.0 \\
\hline & II & 9 & 36.0 \\
\hline & III & 1 & 4.0 \\
\hline & IV & 2 & 8.0 \\
\hline \multirow[t]{3}{*}{ FIGO stage of vaginal carcinoma $(n=10)$} & I & 6 & 60.0 \\
\hline & II & 3 & 30.0 \\
\hline & III & 1 & 10.0 \\
\hline \multirow[t]{3}{*}{ Pathology of cervix and vagina } & Adenocarcinoma & 25 & 69.4 \\
\hline & SCC & 10 & 27.8 \\
\hline & ASC & 1 & 2.8 \\
\hline \multirow[t]{3}{*}{ Urinary tract malformation } & URA & 21 & 58.3 \\
\hline & Others & 2 & 5.6 \\
\hline & No malformation & 13 & 36.1 \\
\hline \multirow[t]{3}{*}{ Genital tract malformation } & HWWS & 8 & 22.2 \\
\hline & Uterus didelphys & 17 & 47.2 \\
\hline & Others & 11 & 30.6 \\
\hline $\begin{array}{l}\text { Sites of carcinoma in patients with } 2 \\
\text { cervices }\end{array}$ & One cervix & 9 & 45.0 \\
\hline \multirow[t]{2}{*}{$(\mathrm{n}=20)$} & Two cervices & 8 & 40.0 \\
\hline & Vagina (no cervix) & 3 & 15.0 \\
\hline
\end{tabular}

*1 carcinoma in situ was not included

Abbreviations: ASC, adenosquamous carcinoma; HWWS,

Herlyn-Werner-Wunderlich syndrome; PUMCH, Peking Union Medical College

Hospital; SCC, squamous-cell carcinoma; URA, unilateral renal agenesis; VB,

vaginal bleeding

\section{Correlation between clinicopathological variables}

The potential correlations between clinicopathological parameters were examined (Table 4). The average age of patients with SCC was 47.0 years, and that of patients with adenocarcinoma or ASC was 36.1 years $(P=0.011)$. Of the 23 patients with urinary tract malformation, $95.7 \%(22 / 23)$ were diagnosed with adenocarcinoma $(n=21)$ or ASC $(n=1)$. Of the 13 patients without urinary tract malformations, four $(30.8 \%)$ were diagnosed with adenocarcinoma. Patients with urinary tract malformations presented with adenocarcinoma significantly more frequently than those without such malformations $(P<0.001)$. Additionally, 15 of 26 patients with adenocarcinoma (57.7\%) had FIGO stage II-IV, while the tumor of one patient with SCC (10\%) was within that range. Patients with adenocarcinoma had a higher probability of presenting with advanced FIGO stage than those with SCC $(P=0.022)$. Notably, all 12 cases of SCC involved the cervix, while 14 of the 24 adenocarcinomas (58.3\%) involved the vagina with or without cervical involvement $(P=0.003)$. Taken together, patients with SCC of the lower genital tract who had genitourinary malformations were older and had earlier stage disease than patients with adenocarcinoma. Compared to patients without urinary tract malformations, those with such malformation may have a predilection for adenocarcinoma of the lower genital tract.

Table 4. Correlation between clinical variables and pathology in patients with genital malformations who developed carcinomas

\begin{tabular}{llll}
\hline Variables & Pathology & & $P$ \\
\hline & SCC & AC/ASC & \\
Age (years) & 47.0 & 36.1 & 0.011 \\
Urinary tract malformation & & & $<0.001$ \\
Yes & 1 & 22 & \\
No & 9 & 4 & 0.022 \\
Stage & & 11 & \\
I & 9 & 15 & 0.003 \\
II-IV & 1 & & \\
Site of carcinoma & & 10 & \\
Cervix & 12 & 14 & \\
Vagina with/without cervix & 0 & & \\
\hline $\begin{array}{l}\text { Abbreviations: AC, adenocarcinoma; ASC, adenosquamous carcinoma; SCC, } \\
\text { squamous-cell carcinoma }\end{array}$ &
\end{tabular}

\section{Treatments and outcomes}

As the sites of carcinoma and stages of disease varied among the patients, their treatment modalities differed significantly. Eleven patients underwent surgery alone, 11 underwent surgery followed by adjuvant radiotherapy or chemotherapy, eight underwent radiotherapy or concomitant chemoradiotherapy, and six underwent radiotherapy (two combined with chemotherapy) followed by surgery. Of the six patients who underwent radiotherapy followed by surgery, two with stage IV disease showed viable carcinoma tissue even after radiotherapy and chemotherapy, therefore, pelvic exenteration was performed in these patients. 
Pathologic results revealed that all six patients who underwent radiotherapy and surgery had residual carcinoma in their surgical specimens even after radiotherapy.

Follow-up information for seven patients from the literature was not available; therefore, we analyzed the outcomes and survival of 29 patients. The median follow-up time was 26 months (range, 2-288 months). Of the 29 patients, four patients died of disease, resulting in a five-year overall survival rate of $80.5 \%$. The 5 -year overall survival rate of patients with adenocarcinoma was $75.6 \%$ and that of patients with SCC was $100 \%$, although the difference was not statistically significant $(P=0.279)$.

\section{Discussion}

In this retrospective study and literature review in which we analyzed the characteristics and outcome of 36 patients with genital tract carcinoma and malformations, we found that $63.9 \%$ of these patients had simultaneous urinary tract malformations while $69.4 \%$ had adenocarcinoma. Moreover, we found that patients with genitourinary tract malformations had a high probability of presenting with adenocarcinoma of the lower genital tract. To our knowledge, our investigation of this rare entity comprises the largest cohort size to date.

The diagnosis of carcinoma of the lower genital tract may be more difficult in women with genital tract malformations than in those without such malformations. First, the clinical presentations of carcinomas in patients with genital malformation may be atypical. Intermenstrual vaginal bleeding is the most common presenting symptom (54.8\%) in patients in the present study. Irregular vaginal bleeding is a common symptom of cervical cancer and genital tract malformations in some patients, and it may lead to a delay in the diagnosis or a potential failure to diagnose carcinoma. Additionally, an anatomic abnormality in the genital tract makes gynecological exams difficult to perform, especially for patients with HWWS. Carcinomas located in the obstructed uterine cervix or vaginal wall in patients with HWWS are occult and difficult to detect. Therefore, it is important for these patients to perform rigorous gynecologic examinations and imaging analyses using investigative tools such as colposcopy, hysteroscopy, laparoscopy, hysterosalpingography, ultrasonography, and MRI.

Because the prevalence of genital tract malformations among the general population is estimated to be $4-7 \%$ [2], it is possible that a similar percentage of women with genital tract cancers may have coexisting malformations. Approximately 15\% of carcinomas of the cervix and vagina in the general population are adenocarcinomas. However, in our 36-patient study, adenocarcinoma accounted for a much higher proportion (69.4\%). Furthermore, all of the vaginal cancers in our study were adenocarcinomas, which was a significant divergence from the $15 \%$ rate in the general population.

Genital and urinary tract developmental anomalies often occur simultaneously owing to the common embryologic origin of these two organ systems. Approximately $20 \%$ of women with genital tract malformations have developmental anomalies of the urinary tract $[3,4]$. However, $63.9 \%$ of patients with carcinoma and malformations in our study had concomitant urinary tract malformation. Renal anomalies were found in 22 of 36 patients studied (61.1\%), with URA being the most common (58.3\%). HWWS is a rare variant of Mullerian duct anomalies, which constitute $7.1 \%$ of all female genital tract malformations [27]. In our study, $22.2 \%$ of patients with carcinomas had HWWS, which was higher than the proportion reported by Acién.

With respect to pathological type, the rate of adenocarcinoma was significantly increased when urinary tract malformations were present. Acién and colleagues found that individuals with URA experience endometriosis more often than those who have both kidneys [28]. However, they did not find an association between gynecological malignancies and URA. In contrast, our results suggest that genitourinary anomalies are linked to an increased risk of adenocarcinoma, although our sample size was too small to draw definitive conclusions. Consistent with our results, Kusunoki and colleagues reported a case of cervical clear cell carcinoma with OHVIRA syndrome, who had no in-utero DES exposure [29].

As to whether patients with congenital genitourinary malformations have a predilection to multiple primary malignant tumors, Woods and colleagues reported a patient with a double vagina, double cervix, uterus didelphys, and URA who had simultaneous uterine endometrial carcinoma and renal cell carcinoma [30]. Vale-Fernandes and colleagues described a woman with a single left kidney, a right unicornuate uterus and a rudimentary left horn; she had complex endometrial hyperplasia with atypia, a bulky fibroid of the left ovary, and bilateral fallopian tube in situ serous carcinoma [31]. In our study, one patient with right URA and uterus didelphys suffered from renal clear cell carcinoma, breast mucinous carcinoma, and vaginal adenocarcinoma within five years. It is therefore conceivable that such congenital malformations are associated with an increased risk of multiple primary cancers, although the total number of patients examined to date is small and no genetic evidence is 
available. Determining the genetic background and risk of developing malignancies in patients with genitourinary malformations is warranted.

Approximately $90 \%$ of lower genital tract carcinomas are caused by persistent infections with carcinogenic high-risk HPV. However, the development of carcinoma in association with congenital malformations of the genitourinary tract is rare. An extensive search of the English literature, no information was found that specifically addressed the association between or concurrence of these entities. Approximately $75 \%$ of patients in our study were negative for HPV, although this statistic was based only on eight patients. It may be interesting to investigate whether high-risk HPV has a role in carcinogenesis in women with congenital genitourinary malformations. The non-viral carcinogenic agents for patients with congenital genitourinary malformations remain unknown.

Based on the link between Müllerian remnants and the development of clear cell carcinoma, Sporri and colleagues, proposed that teratogenic effects may render the Müllerian epithelium sensitive to carcinogenic agents such as DES [10]. They posited that the link between teratogenesis and oncogenesis exemplified Knudson's two-hit theory of carcinogenesis [32]. Carcinogenesis of clear cell carcinoma from Müllerian anomaly is considered, that clear cell carcinoma may have arisen from the paracervix of Müllerian-derived columnar epithelium that have persisted for a long time and was subjected to genetic and hormonal changes [29]. Our findings support their hypothesis that the teratogenic effect combined with cancer genetic susceptibility inordinately predisposes patients to the "second hit", resulting in genital tract carcinomas or even multiple primary malignancies.

Given the rarity of genital carcinomas in patients with genitourinary malformations, we were only able to conduct a retrospective study and literature review. Therefore, it was difficult to avoid selection and publication biases. Despite this limitation, however, our study ought to be valuable for understanding this rare entity given our inclusion of the largest sample size hitherto.

\section{Conclusions}

We have summarized the features and outcomes of carcinoma of the lower genital tract in patients with genital malformations. Adenocarcinomas were diagnosed at younger ages and more advanced stage in patients with such malformations than in the general population, which led to poorer survival rates. Patients with simultaneous malformations of the genital and urinary tract had a high probability of developing adenocarcinoma of the lower genital tract. Additional investigations, preferably involving prospective studies, are warranted to confirm our findings. It is recommended that rigorous gynecologic exams with Pap smears and imaging analyses be performed periodically in women with genital malformations, especially in those with simultaneous urinary malformations, as they may be at risk of developing genital malignancies.

\section{Abbreviations}

AC: adenocarcinoma; ASC: adenosquamous carcinoma; BSO: bilateral salpingo-oophorectomy; CCA: clear cell adenocarcinoma; CCRT: concomitant chemoradiotherapy; CIN: cervical intraepithelial neoplasia; CIS: carcinoma in situ; DDP: cis-dichlorodiammine platinum; DES: diethylstilbestrol; DOD: died of disease; EAC: endometrioid adenocarcinoma; HPV: Human papillomavirus; HWWS: Herlyn-Werner-Wunderlich Syndrome; LSO: left salpingo-oophorectomy; MA: mesonephric adenocarcinoma; MRKH syndrome: Mayer-Rokitansky-Kuster-Hauser syndrome; MRH: modified radical hysterectomy; MRI: magnetic resonance imaging; NA: not available; NED: no evidence of disease; OHVIRA: obstructed hemivagina and ipsilateral renal anomaly; PE: pelvic exenteration; PF: platinum plus 5-fluorouracil; PLA: Pelvic lymphadenectomy; PPLA: pelvic-paraaortic lymphadenectomy; PUMCH: Peking Union Medical College Hospital; PV: partial vaginectomy; SCC: squamous-cell carcinoma; $\mathrm{RH}$ : radical hysterectomy; RSO: right salpingo-oophorectomy; TC: paclitaxel plus carboplatin; TP: pacitaxel plus platinum; TV: total vaginectomy; UD: uterus didelphys; URA: unilateral renal agenesis; VB: vaginal bleeding.

\section{Acknowledgements}

We wish to thank the medical record room staff for their assistance in retrieving the medical records of patients.

\section{Ethics approval and consent to participate}

This study was conducted according to the ethical standards contained in the Declaration of Helsinki, and in national and international guidelines. The study was approved by the Ethics Committee of Peking Union Medical College Hospital. Informed consent to participate in the study was obtained to use of these clinical materials for research purposes.

\section{Consent for publication}

Written consent for publication was obtained from all patients in this study. 


\section{Availability of data and materials}

The datasets used and/or analyzed during the current study available from the corresponding author on reasonable request.

\section{Funding}

This work was supported by grants from the National Natural Science Foundation of China (No. 81772783 and No. 81472446) and the Chinese Academy of Medical Sciences Initiative for Innovative Medicine (CAMS-2017-I2M-1-002). The funding agency has no involvement with the design of the study and collection, analysis, interpretation of data and writing the manuscript.

\section{Authors' contributions}

LZ and YX participated in the design of the study, analyzed and interpreted the patient data. LZ was a major contributor in writing the manuscript. WW and YH performed the histological and imaging examination of carcinoma. NC performed the statistical analysis. The final version of the manuscript has been reviewed and approved for publication by every author.

\section{Competing Interests}

The authors have declared that no competing interest exists.

\section{References}

1. Torre LA, Bray F, Siegel RL, Ferlay J, Lortet-Tieulent J, Jemal A. Global cancer statistics, 2012. CA Cancer J Clin. 2015; 65: 87-108.

2. Grimbizis GF, Gordts S, Di Spiezio Sardo A, Brucker S, De Angelis C, Gergolet $\mathrm{M}$ et al. The ESHRE/ESGE consensus on the classification of female genital tract congenital anomalies. Hum Reprod. 2013; 28: 2032-44.

3. Heinonen PK. Distribution of female genital tract anomalies in two classifications. Eur J Obstet Gynecol Reprod Biol. 2016; 206: 141-6.

4. Scholler D, Holting M, Stefanescu D, Burow H, Schonfisch B, Rall K et al. Female genital tract congenital malformations and the applicability of the ESHRE/ESGE classification: a systematic retrospective analysis of 920 patients. Arch Gynecol Obstet. 2018; 297: 1473-81.

5. Rastogi M, Revannasiddaiah S, Thakur P, Thakur P, Gupta M, Gupta MKet al. Mullerian duct anomalies and their effect on the radiotherapeutic management of cervical cancer. Chin J Cancer. 2013; 32: 434-40.

6. Plesinac-Karapandzic V, Rundic SS, Jankovic R, Nadrljanski M, Milovanovic $\mathrm{Z}$, Tomasevic A et al. Non-diethylstilbestrol exposed vaginal adenocarcinoma in young patients associated with unilateral renal agenesis: two case reports and literature review. Eur J Gynaecol Oncol. 2017; 38: 157-61.

7. Nordqvist SRB, Fidler WJ, Woodruff JM, Lewis JL. Clear cell adenocarcinoma of the cervix and vagina. A clinicopathologic study of 21 cases with and without a history of maternal ingestion of estrogens. Cancer. 1976; 37: 858-71.

8. Sugimori H, Hachisuga T, Nakamura S, Matsuo N, Nakamura G. Cervical cancers in uterus didelphys. Gynecol Oncol. 1990; 36: 439-43.

9. GomezIrizarry FL, Helm CW, Hartman G, Barton DPJ. Unilateral invasive adenosquamous carcinoma of the cervix in a uterus didelphys. J Gynecol Surg. 1996; 12: 213-6.

10. Sporri S, Altermatt HJ, Dreher E, Hanggi W. Clear cell adenocarcinoma of the cervix associated with a rare genitourinary malformation. Obstet Gynecol. 2000; 96: 834-6.

11. Tewari DS, McHale MT, Kuo JV, Monk BJ, Burger RA. Primary invasive vaginal cancer in the setting of the Mayer-Rokitansky-Kuster-Hauser syndrome. Gynecol Oncol. 2002; 85: 384-7.

12. Zeeshanuddin AA. Vaginal clear cell adenocarcinoma with associated Müllerian duct anomalies, renal agenesis and situs inversus: report of a case with no known in-utero exposure with diethyl stilboestrol. J Pak Med Assoc. 2009; 59: 568-70.

13. Uehara T, Onda T, Sasajima $Y$, Sawada M, Kasamatsu T. A case of vaginal clear cell adenocarcinoma complicated with congenital anomalies of the genitourinary tract and metanephric remnant without prenatal diethylstilbestrol exposure. J Obstet Gynaecol Res. 2010; 36: 681-5.

14. Talia KL, Scurry J, Manolitsas T, McCluggage WG. Primary vaginal mucinous adenocarcinoma of gastric type arising in adenosis: a report of 2 cases, 1 associated with uterus didelphys. Int J Gynecol Pathol. 2012; 31: 184-91.

15. Watanabe Y, Etoh T, Nakai H. Adenocarcinoma of the lower female genital tract in patients with Herlyn-Werner-Wunderlich syndrome. Am J Obstet Gynecol. 2012; 207: e5-6.

16. Kaba M, Gungor T, Baser E, Ozdal B, Sirvan L. Cervical cancer in a patient with uterus didelphys and obstructive hemivagina, ipsilateral renal anomaly (OHVIRA) syndrome. Arch Gynecol Obstet. 2013; 288: 229-30.

17. Kawano Y, Nishida M, Kai K, Hirakawa T, Nasu K, Narahara H. Clear cell adenocarcinoma in the uterine cervix associated with malformation of the uterus. J Obstet Gynaecol. 2013; 33: 914-5.

18. Platta CS, Wallace C, Gondi V, Das R, Straub M, Al-Niaimi A et al. Cervical brachytherapy technique for locally advanced carcinoma of the cervix in a patient with septate uterus. J Contemp Brachytherapy. 2014; 6: 76-81.

19. Cordoba A, Escande A, Comte P, Fumagalli I, Bresson L, Mubiayi N et al. Locally advanced adenocarcinoma of the cervix on uterus didelphys: a case report. J Contemp Brachytherapy. 2017; 9: 71-6.

20. Gerbie MV, Weingold AB. Cervical carcinoma in an anomalous uterus. Report of a case. Obstet Gynecol. 1966; 27: 168-70.

21. Corbett PJ, Crompton AC. Invasive carcinoma of one cervix in a uterus didelphys. Case report. Br J Obstet Gynaecol. 1982; 89: 171-2.

22. Fox S, Mones JM, Kronstadt R, Saldana MJ. Bilateral and synchronous squamous cell carcinoma of the cervix in a patient with uterus didelphys. Obstet Gynecol. 1986; 67: 76s-9s.

23. Tam G, Rogers M, Arnold M. Invasive carcinoma of both cervices in a patient with uterus didelphys. Aust N Z J Obstet Gynaecol. 1988; 28: 239-40.

24. Bakri Y, Salem H, Sadi AR, Mansour M. Bilateral and synchronous cervical carcinoma in situ in a didelphic uterus. Int J Gynaecol Obstet. 1992; 37: 289-91.

25. Lee CD, Churn M, Haddad N, Davies-Humphries J, Kingston RK, Jones B. Bilateral radical radiotherapy in a patient with uterus didelphys. Br J Radiol. 2000; 73: 553-6.

26. Loo HW, Locks SM. Squamous cell carcinoma of the cervix: report of an unusual case of bicornuate bicollis uterus treated with bilateral intracavity brachytherapy. Br J Radiol. 2010; 83: e143-6.

27. Acien $\mathrm{P}$, Acien $\mathrm{M}$. The presentation and management of complex female genital malformations. Hum Reprod Update. 2016; 22: 48-69.

28. Acien $P$, Acien $M$. Unilateral renal agenesis and female genital tract pathologies. Acta Obstet Gynecol Scand. 2010; 89: 1424-31.

29. Kusunoki S, Huang K-G, Magno A. Laparoscopic en bloc resection of a para-cervical cancer with OHVIRA syndrome. Taiwanese Journal of Obstetrics and Gynecology. 2018; 57: 141-3.

30. Woods MS, Sheppard RG, Hardman DA, Woods HJ. Congenital genitourinary anomalies. Is there a predilection for multiple primary malignant neoplasms? Cancer. 1992; 69: 546-9.

31. Vale-Fernandes $E_{\text {, Monteiro }} \mathrm{C}_{\text {, Carvalho }} \mathrm{L}_{\text {, Serrano }} \mathrm{P}$. Congenital genitourinary malformation in a woman with three primary gynaecological tumours: synchronous findings never before described. BMJ Case Rep. 2016 Feb 29.

32. Knudson AG, Jr. Mutation and cancer: statistical study of retinoblastoma. Proc Natl Acad Sci U S A. 1971; 68: 820-3. 